\title{
BMJ Open Intimate partner violence experienced by HIV-infected pregnant women in South Africa: a cross-sectional study
}

\author{
Molly Bernstein, ${ }^{1}$ Tamsin Phillips, ${ }^{1}$ Allison Zerbe ${ }^{2}$ James A Mclntyre, ${ }^{1,3}$ \\ Kirsty Brittain, ${ }^{1}$ Greg Petro, ${ }^{4}$ Elaine J Abrams, ${ }^{2,5}$ Landon Myer ${ }^{1}$
}

To cite: Bernstein M, Phillips T, Zerbe A, et al. Intimate partner violence experienced by HIV-infected pregnant women in South Africa: a cross-sectional study. BMJ Open 2016;6: e011999. doi:10.1136/ bmjopen-2016-011999

- Prepublication history for this paper is available online. To view these files please visit the journal online (http://dx.doi.org/10.1136/ bmjopen-2016-011999).

Received 22 March 2016 Revised 22 June 2016 Accepted 28 July 2016

\section{(1) crossark}

${ }^{1}$ Division of Epidemiology \& Biostatistics, School of Public Health \& Family Medicine, University of Cape Town, Cape Town, South Africa ${ }^{2}$ ICAP, Columbia University, Mailman School of Public Health, New York, New York, USA

${ }^{3}$ Anova Health Institute, Johannesburg, South Africa ${ }^{4}$ Department of Obstetrics \& Gynaecology, University of Cape Town, Cape Town, South Africa

${ }^{5}$ College of Physicians \& Surgeons, Columbia University, New York, New York, USA

Correspondence to Professor Landon Myer; landon.myer@uct.ac.za

\section{ABSTRACT}

Objectives: Intimate partner violence (IPV) during pregnancy may be common in settings where HIV is prevalent but there are few data on IPV in populations of HIV-infected pregnant women in Southern Africa. We examined the prevalence and correlates of IPV among HIV-infected pregnant women.

Setting: A primary care antenatal clinic in Cape Town, South Africa.

Participants: 623 consecutive HIV-infected pregnant women initiating lifelong antiretroviral therapy.

Measures: IPV, depression, substance use and psychological distress were assessed using the 13-item WHO Violence Against Women questionnaire, the Edinburgh Postnatal Depression Scale (EPDS), Alcohol and Drug Use Disorders Identification Tests (AUDIT/ DUDIT) and the Kessler 10 (K-10) scale, respectively.

Results: The median age in the sample was 28 years, $97 \%$ of women reported being in a relationship, and $70 \%$ of women reported not discussing and/or agreeing on pregnancy intentions before conception. $21 \%$ of women $(n=132)$ reported experiencing $\geq 1$ act of IPV in the past 12 months, including emotional (15\%), physical $(15 \%)$ and sexual violence $(2 \%)$. Of those reporting any IPV ( $n=132), 48 \%$ reported experiencing 2 or more types. Emotional and physical violence was most prevalent among women aged 18-24 years, while sexual violence was most commonly reported among women aged 25-29 years. Reported IPV was less likely among married women, and women who experienced IPV were more likely to score above threshold for substance use, depression and psychological distress. In addition, women who reported not discussing and/or not agreeing on pregnancy intentions with their partner prior to conception were significantly more likely to experience violence.

Conclusions: HIV-infected pregnant women in the study reported experiencing multiple forms of IPV. While the impact of IPV on maternal and child health outcomes in the context of HIV infection requires further research attention, IPV screening and support services should be considered within the package of routine care for HIV-infected pregnant women.

Trial registration number: NCT01933477.

\section{Strengths and limitations of this study}

- The experiences and correlates of intimate partner violence among HIV-infected pregnant women are not well documented, particularly in sub-Saharan African populations.

- These data demonstrate persistent associations of intimate partner violence with mental health concerns, substance abuse and unplanned pregnancy in this population.

- However, the data are cross-sectional, and thus the temporal nature of these associations requires additional investigation.

\section{BACKGROUND}

Intimate partner violence (IPV) is a major public health concern globally and is associated with negative consequences for victims' physical, mental and reproductive health. ${ }^{1-4}$ Defined as any behaviour within an intimate relationship that causes physical, psychological or sexual harm to those in the relationship, the prevalence of physical and/ or sexual IPV among women in sub-Saharan Africa is commonly estimated to be over $30 \%{ }^{1}$

IPV is associated with a number of negative health sequelae, including psychological distress, alcohol and drug use, unintended pregnancy and an increased risk of HIV infection. ${ }^{1-6}$ In South Africa, experiences of violence appear to be associated with increased sexual risk behaviours and HIV infection. ${ }^{7-9}$ However, while most research has focused on the role of IPV in HIV acquisition, IPV experienced by HIV-infected women warrants particular attention, as IPV and its correlates may play an important role in women's ability to adhere to antiretroviral therapy (ART) both during pregnancy and postpartum. ${ }^{10-14}$

IPV is of particular concern in the context of pregnancy, and the prevalence of physical IPV during pregnancy has been estimated at 
up to $28 \%$ globally. ${ }^{2}$ While the effect of pregnancy on the risk of IPV is debated, ${ }^{15}{ }^{16}$ several studies have suggested that in some settings pregnancy may increase IPV $^{17}$ possibly related to psychosocial and/or economic stressors introduced by unintended pregnancy. One recent study from Durban, South Africa, reported on changes in IPV experiences during pregnancy and post partum, and found levels correlated with specific characteristics of relationships. ${ }^{18}{ }^{19}$ Yet there remain few insights into how diagnosis of HIV status, psychosocial factors, pregnancy intentions and partner involvement in pregnancy planning may be associated with experiences of IPV in pregnancy among HIV-infected women.

Despite the important potential interactions between pregnancy, IPV and HIV, data on IPV in HIV-infected pregnant women are few. We examined the prevalence and correlates of IPV among HIV-infected women seeking antenatal care in Cape Town, South Africa. Our aims were (1) to describe the prevalence of different forms of IPV during the past 12 months and (2) to explore demographic and relationship characteristics and psychological variables as possible correlates of IPV in the past year. As part of this, since a previous HIV diagnosis may represent a significant relationship stressor in this setting, we hypothesised that levels of IPV would be lower in women who did not know their HIV status before the current pregnancy, compared with women who knew that they were HIV positive.

\section{METHODS}

The study setting was a large primary healthcare facility in the community of Gugulethu. This former township in Cape Town is home to 2350000 residents of predominantly low socioeconomic status (SES). Both HIV infection and interpersonal violence are prevalent in this setting, with trauma a leading cause of death among young adults and $\sim 30 \%$ of pregnant women testing HIV positive in local antenatal care services. ${ }^{20}$

This cross-sectional analysis uses data from a multiphase implementation science study evaluating strategies for delivering HIV care and treatment services to HIV-infected women and their children during pregnancy and the postpartum period (NCT01933477). In order to be eligible, HIV-infected pregnant women needed to be at least 18 years of age, not using ART and eligible for ART initiation based on current local guidelines during the study period (from March to June 2013, this was based on CD4 cell count or clinical staging; after June 2013, all HIV-infected pregnant women were ART-eligible regardless of CD4 count or disease stage). Patients were enrolled into the study consecutively and no sampling was conducted.

\section{Measures}

Data were collected by trained interviewers working in a private room adjacent to the antenatal clinic.
Interviewers were from a counselling background with specific training in conducting interviews on sensitive and stigmatised topics, including HIV diagnoses and/or IPV. IPV was assessed using the WHO Violence Against Women questionnaire developed for the WHO Multi-country Study on Women's Health and Domestic Violence against Women. ${ }^{4}$ This 13 -item tool investigates whether participants have experienced specific acts of violence perpetrated by an intimate partner in the past 12 months, with subsections on physical, psychological and sexual violence. Distinctions between moderate and severe physical violence are based on the likelihood of the act of violence resulting in severe harm or injury to the victim.

Timing of HIV diagnosis was based on the participant's self-report as a binary measure of diagnosis during the current pregnancy or before the current pregnancy. A composite SES score was calculated based on the participant's highest level of education, employment, housing type and number of household assets. The standardised scores were then divided into tertiles for the lowest, middle and highest SES groups. ${ }^{21}$ Relationship characteristics were self-reported by participants. Pregnancy intention agreement data were based on whether participants had discussed with their partner and agreed to become pregnant before conception.

Data on alcohol and drug use dependence and/or abuse collected using the Alcohol Use Disorders Identification Test (AUDIT) ${ }^{22}$ and the Drug Use Disorders Identification Test (DUDIT) ${ }^{23}$ which screen for alcohol and drug use and alcohol-related and drug-related problems, respectively. Hazardous drinking was defined as a score of $\geq 3$ using the AUDIT-Consumption (AUDIT-C) scoring system, as previously described for use in women accessing primary care. ${ }^{24}$ Illicit drug use was categorised as 'any drug use' versus 'no drug use' but was not included in multivariate models, given the low proportion of women reporting substance use other than alcohol in this sample.

Psychological distress was measured using the Kessler

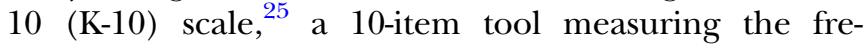
quency of symptoms of non-specific psychological distress, including symptoms of depression and anxiety. Participants with a summed score of $\geq 21.5$ were considered above the threshold for psychological distress, as has been previously described as the optimal threshold among pregnant women in South Africa. ${ }^{26}$ Depression was quantified using the Edinburgh Postnatal Depression Scale (EPDS), ${ }^{27}$ a 10 -item questionnaire assessing depressive symptoms during the previous week. Responses elicited by a frequency scale were summed to generate an overall depression score. A score of $\geq 13$ classified participants as being above the threshold for probable depression, as described in the original development of the scale. ${ }^{27}$ Although originally developed for use in postpartum women, the measure has been validated for use during pregnancy. ${ }^{28}$ 


\section{Ethical considerations}

Throughout the study period, women reporting IPV were referred to a local non-governmental organisation (NGO) offering counselling services and, following local standard of care, counselled on their options to seek protection and redress via the South African Police Service. All participants completed written informed consent prior to study participation.

\section{Data analysis}

Analyses used Stata V.12.0 (Stata Corporation, College Station, Texas, USA). Descriptive statistics of the outcome of interest and all potential correlates were reported for the total sample. Bivariate analyses were conducted using Wilcoxon rank sum tests for continuous variables, and $\chi^{2}$ or Fisher's exact tests for binary variables. All $\mathrm{p}$ values were based on a two-sided $\alpha$ at 0.05 . We stratified estimates of different types of IPV by timing of HIV diagnosis and partner involvement in pregnancy planning in order to better understand the relationships between these variables. Crude logistic regression models tested the associations between total violence, defined as the experience of any form or act of IPV in the past 12 months, and maternal characteristics. Separate multivariable models were built to evaluate the independent associations between IPV and relationship characteristics, and IPV and maternal psychological characteristics. Following standard practice, independent variables were retained in models if they were persistently associated with IPV, and/or if their removal altered associations involving other covariates. Results are presented as ORs with $95 \%$ CIs.

\section{RESULTS}

Between March 2013 and April 2014, 623 women were eligible for this analysis. Women in the sample were aged between 18 and 44 years, with a median age of 28 years, and $97 \%$ reported isiXhosa as their home language. The median gestation at the time of administration of the questionnaire was 26 weeks. Overall, $97 \%$ of participants reported being in a relationship at the time of the interview; one-quarter were married, and $41 \%$ were living with their partner. Over one-third of participants (36\%) reported having disclosed their HIV status to their partner. Relationship duration ranged from 3 months to 20 years, with a median duration of 3 years. The prevalence of probable depression in this sample was $11 \%(\mathrm{n}=68)$, and 35 women $(6 \%)$ scored above the threshold for psychological distress. A total of 162 women $(26 \%)$ reported levels of alcohol use during the past 12 months consistent with hazardous drinking, and 4 women $(0.6 \%)$ reported illicit drug use.

Table 1 shows the prevalence of specific responses to the IPV questionnaire overall and by age category. Overall, $21 \%$ of women $(n=132)$ reported experiencing at least one act of IPV in the preceding 12 months.

Table 1 Reported experiences of intimate partner violence (IPV) during the past 12 months, stratified by age, among HIV-infected pregnant women in Cape Town, South Africa

\begin{tabular}{|c|c|c|c|c|c|c|}
\hline & $\begin{array}{l}\text { All ages } \\
\text { n (\%) }\end{array}$ & $\begin{array}{l}\text { 18-24 } \\
\text { n (\%) }\end{array}$ & $\begin{array}{l}25-29 \\
\text { n (\%) }\end{array}$ & $\begin{array}{l}\text { 30-34 } \\
\text { n (\%) }\end{array}$ & $\begin{array}{l}35+ \\
\text { n (\%) }\end{array}$ & p Value \\
\hline Number of women & 623 & 159 & 221 & 170 & 73 & \\
\hline Any IPV & $132(21)$ & $40(25)$ & $45(20)$ & $33(19)$ & $14(19)$ & 0.554 \\
\hline Emotional violence & $92(15)$ & $28(18)$ & $30(14)$ & $23(14)$ & $11(15)$ & 0.686 \\
\hline Insulted you/made you feel bad & $69(11)$ & $23(14)$ & $20(9)$ & $17(10)$ & $9(12)$ & \\
\hline Belittled/humiliated you & $48(8)$ & $14(9)$ & $17(8)$ & $11(6)$ & $6(8)$ & \\
\hline Scared/intimidated you on purpose & $30(5)$ & $8(5)$ & $7(3)$ & $10(6)$ & $5(7)$ & \\
\hline Threatened to hurt you or someone you care about & $24(4)$ & $5(3)$ & 7 (3) & $8(5)$ & $4(5)$ & \\
\hline Physical violence & $96(15)$ & $31(20)$ & $30(14)$ & $25(15)$ & $10(14)$ & 0.417 \\
\hline Moderate physical violence & $96(15)$ & $31(20)$ & $30(14)$ & $25(15)$ & $10(14)$ & \\
\hline Slapped or threw something at you & $85(14)$ & $26(16)$ & $26(12)$ & $23(14)$ & $10(14)$ & \\
\hline Pushed/shoved you & $57(9)$ & $19(12)$ & $18(8)$ & $14(8)$ & $6(8)$ & \\
\hline Severe physical violence & $43(7)$ & $14(9)$ & $13(6)$ & $11(6)$ & $5(7)$ & \\
\hline Hit you with a fist or something else that could hurt you & $27(4)$ & $6(4)$ & $8(4)$ & $9(5)$ & $4(5)$ & \\
\hline Kicked you, dragged you or beat you up & $28(4)$ & $11(7)$ & $8(4)$ & $7(4)$ & $2(3)$ & \\
\hline Choked or burnt you on purpose & $18(3)$ & $5(3)$ & $6(3)$ & $6(4)$ & $1(1)$ & \\
\hline $\begin{array}{l}\text { Threatened to use or used a gun, knife or other weapon } \\
\text { against you }\end{array}$ & $8(1)$ & $4(3)$ & $1(0.5)$ & $3(2)$ & 0 & \\
\hline Sexual violence & $14(2)$ & $1(0.6)$ & $9(4)$ & $3(2)$ & $1(1)$ & $0.147^{\star}$ \\
\hline $\begin{array}{l}\text { Physically forced you to have sexual intercourse when you did } \\
\text { not want to }\end{array}$ & $14(2)$ & $1(0.6)$ & $9(4)$ & $3(2)$ & $1(1)$ & \\
\hline $\begin{array}{l}\text { Had unwanted sexual intercourse because you were afraid of } \\
\text { what he might do }\end{array}$ & $8(1)$ & 0 & $5(2)$ & $2(1)$ & $1(1)$ & \\
\hline $\begin{array}{l}\text { Forced you to do something sexual that you found degrading or } \\
\text { humiliating }\end{array}$ & $5(0.8)$ & $1(0.6)$ & $3(1)$ & 0 & $1(1)$ & \\
\hline
\end{tabular}


Figure 1 Venn diagram of types

of violence experienced during

past 12 months among

HIV-infected pregnant women in

Cape Town, South Africa. IPV, intimate partner violence.

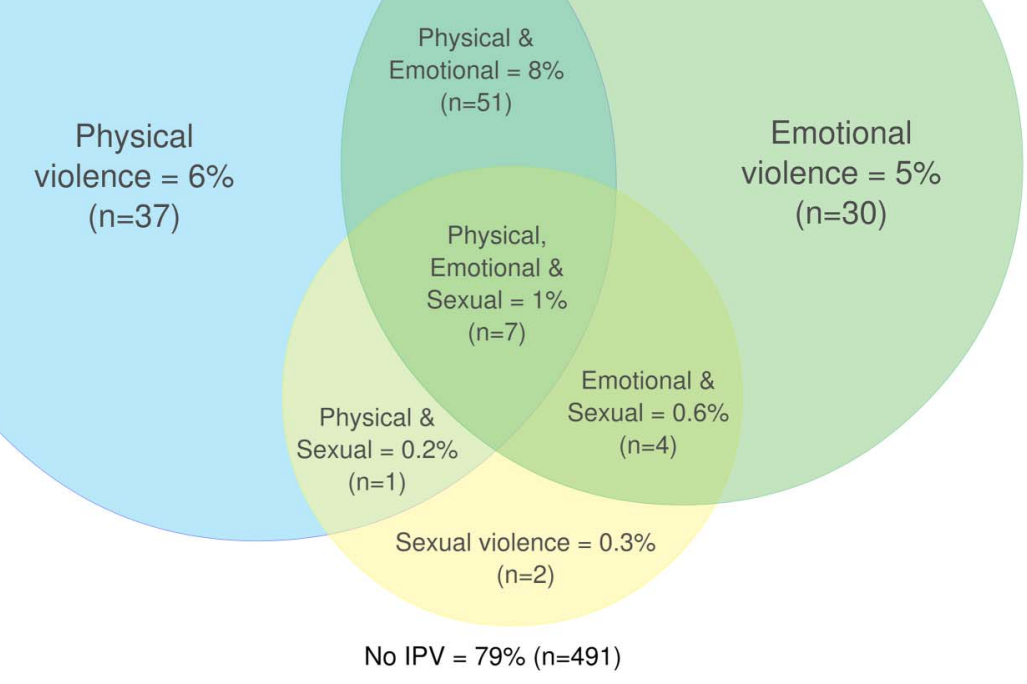

Specifically, $15 \%(\mathrm{n}=92)$ reported emotional violence, $15 \% \quad(n=96)$ reported physical violence (classified as severe violence in $7 \%$ of women) and $2 \% \quad(n=14)$ reported sexual violence. Emotional and physical violence was most prevalent among 18-24 year-olds and sexual violence was most commonly reported among women aged 25-29 years. Of those who reported IPV, 63 participants $(10 \%$ of the overall sample and $48 \%$ of those who reported any IPV) experienced two or more types of violence in the last year; the most common combination of violence was physical and emotional violence, reported by $8 \%$ of women $(n=51)$ (figure 1$)$.

Table 2 describes the prevalence of any IPV by women's demographic and relationship characteristics. In bivariate analyses, women who reported IPV in the past year were less likely to be married, and more likely to use illicit drugs and to score above the threshold for hazardous alcohol use, psychological distress and depression. Those who experienced violence were also more likely to have not discussed pregnancy with their partner and/or not agreed with their partner to become pregnant prior to conception, compared with women who had not experienced violence.

Table 3 shows the results of logistic regression models examining the association between any reported IPV and participant relationship characteristics (model A) and psychological variables (model B). Among relationship characteristics, being married appeared protective against IPV in both unadjusted analyses and after adjusting for age and SES (adjusted OR 0.52; 95\% CI 0.30 to $0.91)$. The association between IPV and women's discussing and/or agreeing to the pregnancy with their partner was significant in the unadjusted model, but the association did not reach statistical significance in the adjusted model (adjusted OR 1.33; 95\% CI 0.82 to 2.14). Among psychological variables, there were strong and persistent associations between IPV and hazardous alcohol use (OR 3.49; 95\% CI 2.29 to 5.33), psychological distress (OR 3.64; 95\% CI 1.68 to 7.86) and depression (OR 2.06; $95 \%$ CI 1.15 to 3.68$)$.

Table 4 shows the distribution of types of IPV according to women's discussion of pregnancy with their partner. Women who reported discussing pregnancy and agreeing on the pregnancy with their partner prior to conception were significantly less likely to report experiencing violence overall $(\mathrm{p}=0.029)$ and physical violence specifically $(\mathrm{p}=0.010)$ compared with women who had either not discussed or not agreed to the pregnancy with their partner prior to conception. However, the prevalence of emotional violence was only slightly lower in women who discussed and agreed on the pregnancy with their partner, and levels of sexual violence were similar in both groups. When stratified by timing of HIV diagnosis, no associations were observed between discussion around pregnancy and reported IPV among women who were diagnosed during the current pregnancy. However, the associations between discussion around pregnancy and overall violence $(\mathrm{p}=0.028)$ as well as physical violence specifically $(p=0.027)$ remained significant among women diagnosed prior to the current pregnancy.

\section{DISCUSSION}

These data demonstrate a significant burden of IPV in this population of HIV-infected pregnant women, with $21 \%$ reporting any IPV in the preceding 12 months. Of those who reported violence, $48 \%$ experienced two or more types, most often both physical and emotional violence $(8 \%$ of the sample). Women who experienced 
Table 2 Association between reported experiences of any IPV during the past 12 months and participant characteristics among HIV-infected pregnant women in Cape Town, South Africa

\begin{tabular}{|c|c|c|c|c|}
\hline & $\begin{array}{l}\text { Total } \\
\text { n (\%) }\end{array}$ & $\begin{array}{l}\text { Any IPV } \\
\mathrm{n}(\%)\end{array}$ & $\begin{array}{l}\text { No IPV } \\
\text { n (\%) }\end{array}$ & p Value \\
\hline Number of women & 623 & 132 & 491 & \\
\hline \multicolumn{5}{|l|}{ Demographic and relationship characteristics } \\
\hline Median age (IQR) & $28(24-32)$ & $28(24-31)$ & $28(25-32)$ & $0.237^{*}$ \\
\hline \multicolumn{5}{|l|}{ Socioeconomic status } \\
\hline Highest & $214(34)$ & $46(35)$ & $168(34)$ & \\
\hline Middle & $226(36)$ & $41(31)$ & $185(38)$ & \\
\hline Lowest & $183(29)$ & $45(34)$ & $138(28)$ & 0.281 \\
\hline \multicolumn{5}{|l|}{ Time of first HIV-positive test } \\
\hline During current pregnancy & $342(55)$ & $75(57)$ & $267(54)$ & \\
\hline Before current pregnancy & $281(45)$ & $57(43)$ & $224(46)$ & 0.617 \\
\hline Currently in a relationship & $606(97)$ & $25(95)$ & $481(98)$ & $0.064 \dagger$ \\
\hline Married to partner $(n=606)$ & $151(25)$ & $19(15)$ & $132(27)$ & 0.005 \\
\hline Cohabiting with partner $(n=606)$ & $246(41)$ & $44(35)$ & $202(42)$ & 0.168 \\
\hline Median relationship duration in years (IQR; $n=606$ ) & $3(2-6)$ & $3(2-6)$ & $3(2-6)$ & 0.569 \\
\hline HIV status disclosed to partner $(n=606)$ & $217(36)$ & $44(35)$ & $173(36)$ & 0.873 \\
\hline Report of other sexual partner(s) during past 12 months & $102(16)$ & $25(19)$ & 77 (16) & 0.369 \\
\hline \multicolumn{5}{|l|}{ Pregnancy intention agreement with partner $(n=614)$} \\
\hline Discussed and agreed & $185(30)$ & $29(22)$ & $156(32)$ & \\
\hline Not discussed and/or not agreed & $429(70)$ & $101(78)$ & $328(68)$ & 0.029 \\
\hline \multicolumn{5}{|l|}{ Psychological variables } \\
\hline Alcohol use (AUDIT-C), above threshold ( $\geq 3$ ) & $162(26)$ & $62(47)$ & $100(20)$ & $<0.001$ \\
\hline Any drug use (DUDIT) & $4(0.6)$ & $3(2)$ & $1(0.2)$ & $0.032 \dagger$ \\
\hline Psychological distress $(\mathrm{K}-10)$, above threshold $(\geq 21.5)$ & $35(6)$ & $18(14)$ & $17(3)$ & $<0.001$ \\
\hline Depression (EPDS), above threshold ( $\geq 13$ ) & $68(11)$ & $27(20)$ & $41(8)$ & $<0.001$ \\
\hline
\end{tabular}

violence were more likely to be unmarried, substance users, and to score above the threshold for psychological distress and depression. Not discussing and/or not agreeing on pregnancy with a male partner prior to conception was found to be significantly associated with experience of any form of IPV, and with physical IPV specifically, among women diagnosed with HIV before the current pregnancy.

The estimated past-year prevalence of any type of IPV in this setting $(21 \%)$ is notable and in keeping with previous reports from South Africa. ${ }^{10}{ }_{29}^{30}$ Extending beyond previous reports, we were able to distinguish specific forms of IPV, and found that the reported prevalence of sexual IPV specifically was markedly lower than other types of IPV (2\%); this appears consistent with previous research. ${ }^{16}{ }^{30}$ Women's demographic characteristics did not appear to be strong predictors of IPV, consistent with reviews from the region which have reported mixed findings on the impact of demographics on IPV risk. ${ }^{29}$ In addition, experiences of IPV in the previous 12 months were consistently associated with mental health variables, including psychological distress, depressive symptoms and substance use. These findings were independent of women's demographic characteristics, in keeping with previous research, ${ }^{31-33}$ and pointing to the significant psychological comorbidity of IPV.
During this analysis, we hypothesised that a previous HIV diagnosis would represent a significant relationship stressor, and in turn that levels of IPV in the previous 12 months would be lower in women who did not know their HIV status before the pregnancy, compared with women who knew that they were HIV positive. This was based on previous findings that an HIV diagnosis may serve as a significant trigger for IPV in many relationships. ${ }^{34}$ However, we found no difference in IPV prevalence between women who had been diagnosed with HIV previously compared with those newly diagnosed during the current pregnancy. It is possible that many women do not disclose their HIV status to partners or, if they do, that the risk of experiencing IPV in this population of women is not modified by knowledge of HIV diagnosis. While HIV remains stigmatised in this setting, the prevalence of HIV may mean that an HIV diagnosis is not a specific relationship stressor independent of other relationship and sociodemographic factors. We do not have data on disclosure prior to reported IPV, however, and further research is required to explore this finding.

In addition, these results suggest that women who reported IPV in the preceding 12 months were more likely to have either not discussed pregnancy with their partner, or not agreed with their partner to become 
Table 3 Logistic regression models of factors associated with reported experiences of any IPV during the past 12 months, among HIV-infected pregnant women in Cape Town, South Africa

\begin{tabular}{|c|c|c|c|c|}
\hline & Unadjusted OR (95\% Cl) & p Value & Adjusted OR (95\% Cl) & p Value \\
\hline \multicolumn{5}{|c|}{ (A) Model of demographic and relationship characteristics, adjusted for age and SES } \\
\hline Age & $0.98(0.94$ to 1.01$)$ & 0.231 & $0.99(0.95$ to 1.03$)$ & 0.562 \\
\hline \multicolumn{5}{|l|}{ SES } \\
\hline Highest & 1.0 & & 1.0 & \\
\hline Middle & $0.81(0.51$ to 1.29$)$ & 0.378 & $0.86(0.52$ to 1.40$)$ & 0.543 \\
\hline Lowest & $1.19(0.75$ to 1.90$)$ & 0.465 & $1.28(0.79$ to 2.10$)$ & 0.319 \\
\hline \multicolumn{5}{|l|}{ Marital status } \\
\hline Not married & 1.0 & & 1.0 & \\
\hline Married & $0.47(0.28$ to 0.80$)$ & 0.006 & $0.52(0.30$ to 0.91$)$ & 0.021 \\
\hline \multicolumn{5}{|l|}{ Pregnancy intention } \\
\hline Discussed and agreed & 1.0 & & 1.0 & \\
\hline Not discussed and/or not agreed & $1.66(1.05$ to 2.61$)$ & 0.030 & $1.33(0.82$ to 2.14$)$ & 0.248 \\
\hline \multicolumn{5}{|l|}{ Time of first HIV-positive test } \\
\hline During this pregnancy & 1.0 & & & \\
\hline Before this pregnancy & 0.91 (0.61 to 1.33$)$ & 0.617 & & \\
\hline \multicolumn{5}{|c|}{ (B) Model of psychological measures, adjusted for age and SES } \\
\hline Age & $0.98(0.94$ to 1.01$)$ & 0.231 & 0.99 (0.95 to 1.03$)$ & 0.660 \\
\hline \multicolumn{5}{|c|}{, } \\
\hline Highest & 1.0 & 0.378 & 1.0 & 0.985 \\
\hline Middle & $0.81(0.51$ to 1.29$)$ & 0.465 & $1.00(0.60$ to 1.65$)$ & 0.076 \\
\hline Lowest & $1.19(0.75$ to 1.90$)$ & & 1.59 (0.95 to 2.64$)$ & \\
\hline \multicolumn{5}{|l|}{ Alcohol use (AUDIT-C) } \\
\hline Below threshold & 1.0 & $<0.001$ & 1.0 & $<0.001$ \\
\hline Above threshold $(\geq 3)$ & $3.46(2.31$ to 5.20$)$ & & $3.49(2.29$ to 5.33$)$ & \\
\hline \multicolumn{5}{|l|}{ Psychological distress (K-10) } \\
\hline Below threshold & 1.0 & $<0.001$ & 1.0 & 0.001 \\
\hline Above threshold & 4.40 (2.20 to 8.81$)$ & & $3.64(1.68$ to 7.86$)$ & \\
\hline \multicolumn{5}{|l|}{ Depression (EPDS) } \\
\hline Below threshold & 1.0 & $<0.001$ & 1.0 & 0.015 \\
\hline Above threshold $(\geq 13)$ & $2.82(1.66$ to 4.80$)$ & & $2.06(1.15$ to 3.68$)$ & \\
\hline
\end{tabular}

pregnant, prior to conception. This association did not persist after adjustment for demographic and other relationship characteristics, but is still intriguing in suggesting how IPV risk may be increased during pregnancy for many women. Recognising that a large fraction of pregnancies are unintended in South Africa and globally, ${ }^{5} 29$ understanding how relationship dynamics and IPV risk may be modified by pregnancy in different contexts is an important avenue for future research. Further, our results suggest that the association between discussion around pregnancy and experiencing IPV may be modified by the timing of HIV diagnosis, with this association only observed among women who were diagnosed prior to pregnancy.

This analysis is subject to a number of important limitations. This is a cross-sectional study that cannot establish the temporal relationship between IPV and associated risk factors. Furthermore, the nature of the WHO questionnaire used to measure IPV does not allow us to establish the frequency of violent acts, the nature of a woman's relationship with a perpetrator, nor the timing in relation to the current pregnancy. Related to this, we assessed IPV in the late second and early third trimester (median, 26 weeks gestation), and it is possible that additional experiences of violence during pregnancy were not detected due to this timing. More detailed information regarding violence before, during and after pregnancy specifically would shed more light on the effects of pregnancy on the risk of IPV. In addition, under-reporting is a common concern in this type of research, due to the sensitivity and stigma often associated with violence. ${ }^{29}$ It is well documented that IPV, especially of a sexual nature, is a major source of stigma that may be a barrier to reporting. ${ }^{5}$ In this study, we made every effort to reduce the possibility of under-reporting through interviewer training, use of private interview space and assurances of appropriate confidentiality, but some under-reporting may be inevitable.

Despite these limitations, this research is one of the few studies to look at IPV specifically among women living in sub-Saharan Africa in the context of two welldocumented risk factors for IPV: pregnancy and HIV infection. The prevalence estimates shown here suggest that IPV during pregnancy is a significant burden in this population of women. Coupled with the strong 
Table 4 Association between intimate partner violence (IPV) during the past 12 months and partner discussion and agreement around pregnancy intention, stratified by timing of HIV diagnosis, among HIV-infected pregnant women in Cape Town, South Africa

\begin{tabular}{|c|c|c|c|c|}
\hline & $\begin{array}{l}\text { Total } \\
\text { n (\%) }\end{array}$ & $\begin{array}{l}\text { Discussed } \\
\text { and agreed } \\
\mathrm{n}(\%)\end{array}$ & $\begin{array}{l}\text { Did not discuss } \\
\text { and/or agree } \\
\text { n (\%) }\end{array}$ & p Value \\
\hline \multicolumn{5}{|l|}{ Total sample } \\
\hline Number of women & 614 & 185 & 429 & \\
\hline Any IPV & $130(21)$ & $29(16)$ & $101(24)$ & 0.029 \\
\hline Emotional violence & $90(15)$ & $21(11)$ & 69 (16) & 0.128 \\
\hline Physical violence & $95(15)$ & $18(10)$ & $77(18)$ & 0.010 \\
\hline Sexual violence & $14(2)$ & $3(2)$ & $11(3)$ & $0.569^{\star}$ \\
\hline \multicolumn{5}{|c|}{ Diagnosed during current pregnancy } \\
\hline Number of women & 337 & 108 & 229 & \\
\hline Any IPV & $74(22)$ & $20(19)$ & $54(24)$ & 0.295 \\
\hline Emotional violence & $52(15)$ & $15(14)$ & $37(16)$ & 0.591 \\
\hline Physical violence & $52(15)$ & $12(11)$ & $40(17)$ & 0.132 \\
\hline Sexual violence & $8(2)$ & $3(3)$ & $5(2)$ & $0.714^{*}$ \\
\hline \multicolumn{5}{|c|}{ Diagnosed before current pregnancy } \\
\hline Number of women & 277 & 77 & 200 & \\
\hline Any IPV & $56(20)$ & $9(12)$ & $47(24)$ & 0.028 \\
\hline Emotional violence & $38(14)$ & $6(8)$ & $32(16)$ & 0.075 \\
\hline Physical violence & $43(16)$ & $6(8)$ & 37 (19) & 0.027 \\
\hline Sexual violence & $6(2)$ & $0(0)$ & $6(3)$ & $0.191^{\star}$ \\
\hline
\end{tabular}

associations between IPV and mental health variables, this points to a major need for health services strengthening in this area. Specifically, programmes and policies that support the identification of and support for women experiencing IPV are required; these services may be particularly important in the context of pregnancy where there may be separate sequelae for mothers and infants over the long term. ${ }^{2} 1733$ While screening programmes alone do not reduce IPV risk, screening paired with appropriate interventions has been shown to significantly lower future risk of IPV, including one programme showing efficacy in South Africa. ${ }^{34}$ As most pregnant women in South Africa attend at least four antenatal visits; thus, interventions in maternal health settings, specifically those geared towards HIV-infected women, offer an ideal point of access to this highly vulnerable population.

\section{CONCLUSION}

In summary, these data demonstrate an appreciable prevalence of IPV, and specifically physical and emotional violence, in this population of HIV-infected pregnant women. The prevalence of IPV in this study suggests that this is a high-risk population accessing health services requiring continued efforts to further understand and optimise care. While the potential impact of IPV and related factors on ART adherence over time requires further research, IPV-related screening and appropriate support services need to be considered as part of the package of care for ART in pregnancy.
Acknowledgements The authors would like to thank Cathy Kalombo and Anik Gevers for their contributions to this work.

Contributors MB conducted the analysis, led data interpretation and drafted the manuscript. TP directed data collection and assisted with analysis and data interpretation. AZ directed data collection and assisted with data interpretation. JAM assisted in conceptualising the study and data interpretation. KB assisted with analysis and data interpretation. EJA and LM conceptualised the study and assisted with data interpretation. All the authors read and approved the final manuscript.

Funding This research was supported by the President's Emergency Plan for AIDS Relief (PEPFAR) through the Eunice Kennedy Shriver National Institute of Child Health and Human Development (NICHD) under award number 1R01HD074558. Additional funding comes from the Elizabeth Glaser Pediatric AIDS Foundation.

Competing interests None declared.

Ethics approval Ethical clearance for the study was obtained from the University of Cape Town Human Research Ethics Committee and the Institutional Review Board at Columbia University Medical Center.

Provenance and peer review Not commissioned; externally peer reviewed.

Data sharing statement All study variables reported here are available in a de-identified form from the principal investigators, who may be contacted via email for more information (landon.myer@uct.ac.za or eja1@columbia.edu).

Open Access This is an Open Access article distributed in accordance with the Creative Commons Attribution Non Commercial (CC BY-NC 4.0) license, which permits others to distribute, remix, adapt, build upon this work noncommercially, and license their derivative works on different terms, provided the original work is properly cited and the use is non-commercial. See: http:// creativecommons.org/licenses/by-nc/4.0/

\section{REFERENCES}

1. World Health Organization. Global and regional estimates of violence against women: prevalence and health effects of intimate partner violence and non-partner sexual violence. World Health Organization, 2013; Report No.: 9789241564625. 
2. World Health Organization, Pan American Health Organization. Understanding and addressing violence against women: intimate partner violence. World Health Organization, 2012.

3. World Health Organization, London School of Hygiene and Tropical Medicine. Preventing intimate partner and sexual violence against women: taking action and generating evidence. Geneva: World Health Organization, 2010; Report No.: 9789241564007.

4. Garcia-Moreno CJ, Jansen $\mathrm{H}$, Ellsberg M, et al. WHO multi-country study on women's health and domestic violence against women. World Health Organization, 2005.

5. South African National Department of Health. South Africa Demographic \& Health Survey 1998. Pretoria: NDOH, 2002.

6. Campbell JC. Health consequences of intimate partner violence. Lancet 2002;359:1331-6.

7. Dunkle KL, Jewkes RK, Brown HC, et al. Gender-based violence, relationship power, and risk of HIV infection in women attending antenatal clinics in South Africa. Lancet 2004;363:1415-21.

8. Peltzer K, Jones D, Weiss SM, et al. Sexual risk, serostatus and intimate partner violence among couples during pregnancy in rural South Africa. AIDS Behav 2013;17:508-16.

9. Maman S, Campbell J, Sweat MD, et al. The intersections of HIV and violence: directions for future research and interventions. Soc Sci Med 2000;50:459-78.

10. Groves AK, Kagee A, Maman S, et al. Associations between intimate partner violence and emotional distress among pregnant women in Durban, South Africa. J Interpers Violence 2012;27:1341-56.

11. Lopez EJ, Jones DL, Villar-Loubet OM, et al. Violence, coping, and consistent medication adherence in HIV-positive couples. AIDS Educ Prev 2010;22:61-8.

12. Blashill AJ, Perry N, Safren SA. Mental health: a focus on stress, coping, and mental illness as it relates to treatment retention, adherence, and other health outcomes. Curr HIVIAIDS Rep 2011;8:215-22.

13. Nachega JB, Uthman OA, Anderson J, et al. Adherence to antiretroviral therapy during and after pregnancy in low-income, middle-income, and high-income countries: a systematic review and meta-analysis. AIDS 2012;26:2039-52.

14. Watts C, Seeley J. Addressing gender inequality and intimate partner violence as critical barriers to an effective HIV response in sub-Saharan Africa. J Int AIDS Soc 2014;17:19849.

15. Shamu S, Abrahams N, Temmerman M, et al. "That pregnancy can bring noise into the family": exploring intimate partner sexual violence during pregnancy in the context of HIV in Zimbabwe. PLOS ONE 2012;7:e43148.

16. Shamu S, Abrahams N, Zarowsky C, et al. Intimate partner violence during pregnancy in Zimbabwe: a cross-sectional study of prevalence, predictors and associations with HIV. Trop Med Int Health 2013;18:696-711.

17. Koen N, Wyatt GE, Williams JK, et al. Intimate partner violence: associations with low infant birthweight in a South African birth cohort. Metab Brain Dis 2014;29:281-99.

18. Groves AK, McNaughton Reyes L, Foshee V, et al. Relationship factors and trajectories of intimate partner violence among South African women during pregnancy and the postpartum period. PLOS ONE 2014;9:e106929.
19. Groves AK, Moodley D, McNaughton Reyes L, et al. Prevalence, rates and correlates of intimate partner violence among South African women during pregnancy and the postpartum period. Matern Child Health J 2015;19:487-95.

20. Myer L, Phillips TK, Zerbe A, et al. Optimising antiretroviral therapy (ART) for maternal and child health (MCH): rationale and design of the MCH-ART study. J Acquir Immune Defic Syndr 2016;72(Suppl 2):189-96.

21. Myer L, Stein DJ, Grimsrud A, et al. Social determinants of psychological distress in a nationally-representative sample of South African adults. Soc Sci Med 2008;66:1828-40.

22. Saunders JB, Aasland OG, Babor TF, et al. Development of the Alcohol Use Disorders Identification Test (AUDIT): WHO Collaborative Project on Early Detection of Persons with Harmful Alcohol Consumption-Il. Addiction 1993;88:791-804.

23. Berman $\mathrm{AH}$, Bergman $\mathrm{H}$, Palmstierna $\mathrm{T}$, et al. Evaluation of the Drug Use Disorders Identification Test (DUDIT) in criminal justice and detoxification settings and in a Swedish population sample. Eur Addict Res 2005;11:22-31.

24. Bradley KA, DeBenedetti AF, Volk RJ, et al. AUDIT-C as a brief screen for alcohol misuse in primary care. Alcohol Clin Exp Res 2007;31:1208-17.

25. Kessler RC, Andrews G, Colpe LJ, et al. Short screening scales to monitor population prevalences and trends in non-specific psychological distress. Psychol Med 2002;32:959-76.

26. Spies G, Stein DJ, Roos A, et al. Validity of the Kessler 10 (K-10) in detecting DSM-IV defined mood and anxiety disorders among pregnant women. Arch Womens Ment Health 2009;12:69-74.

27. Cox JL, Holden JM, Sagovsky R. Detection of postnatal depression. Development of the 10-item Edinburgh Postnatal Depression Scale. Br J Psychiatry 1987;150:782-6.

28. Murray D, Cox JL. Screening for depression during pregnancy with the Edinburgh Depression Scale (EPDS). J Reprod Infant Psychol 1990;8:99-107.

29. Shamu S, Abrahams N, Temmerman M, et al. A systematic review of African Studies on intimate partner violence against pregnant women: prevalence and risk factors. PLOS ONE 2011;6: e17591.

30. Stein DJ, Koen N, Donald KA, et al. Investigating the psychosocial determinants of child health in Africa: the Drakenstein Child Health Study. J Neurosci Methods 2015;252:27-35.

31. Nduna M, Jewkes RK, Dunkle KL, et al. Associations between depressive symptoms, sexual behaviour and relationship characteristics: a prospective cohort study of young women and men in the Eastern Cape, South Africa. J Int AIDS Soc 2010;13:44.

32. Jina R, Jewkes R, Hoffman $S$, et al. Adverse mental health outcomes associated with emotional abuse in young rural South African women: a cross-sectional study. J Interpers Violence 2012;27:862-80.

33. Eaton LA, Kalichman SC, Sikkema KJ, et al. Pregnancy, alcohol intake, and intimate partner violence among men and women attending drinking establishments in a Cape Town, South Africa township. J Community Health 2012;37:208-16.

34. Hatcher AM, Woollett N, Pallitto CC et al. Bidirectional links between HIV and intimate partner violence in pregnancy: implications for prevention of mother-to-child transmission. J Int AIDS Soc 2014;17:19233. 